\title{
EVALUATING THE NEED FOR TRAUMA-INFORMED CARE IN A BEHAVIORAL HEALTH SYSTEM OF CARE
}

\author{
Megan J. Freeman and John Young \\ University of Mississippi
}

Kayla Erickson, Elizabeth Frizsell, and John Damon

Mississippi Children's Home Services

\section{Kathy Crockett}

\section{Hinds Behavioral Health Services}

\begin{abstract}
Potentially traumatic events (PTE) can occur in the life of an individual and can cause long-term psychological harm, including symptoms or diagnosis of posttraumatic stress disorder (PTSD). A large number of youth currently receiving mental and behavioral health services have been exposed to PTE, and a subset of those struggle with distressing and impairing symptoms of PTSD. Often, these youth have not and will not receive appropriate care, which can include Trauma-Focused Cognitive Behavioral Therapy (TF-CBT) and traumainformed care (e.g., Sanctuary). We sought to identify rates of exposure to PTE and expression of PTSD symptoms in youth receiving services in a system of care and found that 95\% of the sample reported exposure to at least one PTE (mean $=5)$. One third of the sample reported a significant burden of PTSD symptoms (5 or more rated highly in the past month). These findings support the traumainformed care principle of universal precautions in environments that provide mental and behavioral health services to youth. Case vignettes are presented and implications for practice are discussed.
\end{abstract}

The description of negative emotional reactions following exposure to a potentially traumatic event (PTE) has a history as long as that of attempts to describe and classify mental disorders more generally (Monson \& Friedman, 2006). Modern cognitive behavioral models (i.e., those built on examination of the reciprocal interaction between thoughts, feelings, and behaviors; Beck, 2011) can be used to aid the understanding of these reactions. In combination with decades of research focused on factors that contribute to the origin and maintenance of posttraumatic stress disorder (PTSD), these models provide a context to understand how both children and adults can become psychologically burdened as a consequence of PTE. Functional impairment, for example, has been notable in many individuals exposed to PTE in terms of concentration, memory, mood, sleep, physiological arousal, and the ability to form and adequately maintain social relationships. Although until recently PTSD was classified as an anxiety disorder in the DSMIV-TR (2000), recent taxonomists now view it as a more complex experience that 
involves many different types of emotions and experiences beyond anxiety and anxious arousal (DSM-5, 2013; Riggs, Cahill, \& Foa, 2006).

Decades of research have afforded considerable understanding of the disorder, and conceptualizations of its etiology based on scientific evidence are notable (e.g., Ehlers \& Clark, 2000). Although other emotions are now thought to play prevalent roles, fear continues to be conceived as the primary emotion driving the development and maintenance of PTSD symptoms. For example, after experiencing a PTE, a child may develop an unhealthy fear related to stimuli that remind him or her of what happened, even if the stimulus is something that would not necessarily provoke fear in another individual. The fear grows stronger when the child mentally or physically avoids salient reminders of the event. In cognitive terms, this avoidance enables short-term reduction of negative emotions prompted by the event while simultaneously reinforcing the idea that such experiences are dangerous or scary. This process can extend to include related stimuli that were not present at the time of the event but because they are similar to the originally feared stimulus (i.e., generalization). Additionally, children may vividly remember feelings and thoughts that they had at the time of the event (e.g., horror, anger, sadness, "I will die,"), and reexperience them in association with their memories of the event, which in turn increases fear and negative reactions to the memory and any reminders (Gonzalez-Prendes \& Resko, 2012). In this way, PTSD symptoms emerge and grow over time, becoming more and more impairing in the life of the child. Many distressed youth serviced in publicly funded systems of care are affected by these symptoms but are, ironically, among the least likely to receive appropriate services for their difficulties, as the following example makes poignant:

\section{Case example}

Destiny is a 13-year-old female who was removed from her mother's care after being sexually assaulted by her mother's boyfriend. Child Protective Services found evidence of repeated abuse, and she is now undergoing care at a residential treatment center. Destiny struggles with anger and is having difficulty forming positive relationships with either male or female staff members. She is particularly suspicious of the male staff members and becomes hypervigilant whenever one is present. Recently, Destiny was put into a physical restraint after a male staff member startled her while she was in the common area working on her homework. She immediately became physically aggressive, and staff were unable to calm her. Destiny later told her therapist that this situation prompted vivid recall of one of the occasions on which she was raped, which led to her feeling as if she were being attacked again. This in turn led to her immediate reaction of attempting to defend herself, which was amplified when the male staff member placed her into a physical hold. She explained to her therapist that it was only after she was released from the restraint and calmed down that she realized where she was and what had happened. This led to her feeling ashamed about how she had reacted, and to confu- 
sion over the enduring nature of her emotional responses to this kind of situation. At the next day's staff meeting, all the staff agreed that they had not realized the extent to which Destiny's prior experience of sexual assault was affecting her currently. Each member of her treatment team expressed strong empathy for Destiny and wanted to help her feel safe in the treatment environment. Their consensus opinion, however, was also that no one knew what to do to help her, neither in terms of specific psychological treatment nor environmental modification.

This depiction exemplifies the type of problems encountered in systems of care, as well as the difficulties inherent in intervention. For example, well-intentioned staff who identify the extremely difficult nature of Destiny's symptoms in the example above do not have a model to anticipate, prevent, or otherwise adjust the environment to address her suffering. Had their facility been structured around trauma-informed care principles, they would have had procedures in place to deal with her behavior in the context of reexperiencing as a symptom of PTSD, and they could have avoided Destiny's retraumatization through use of a physical restraint. Destiny's experience is unfortunately common, however, and the salience of exposure to PTE in youth development and mental health service delivery cannot be overstated. Base rates suggest that up to $60 \%$ of community-dwelling children have been exposed to abuse, violence, and other crimes (Finkelhor, Turner, Ormrod, \& Hamby, 2009), with much higher rates observed in high-risk samples, such as $93 \%$ of youth entering detention (Abram et al., 2004) and 95\% of residential treatment (Harr, Horn-Johnson, Williams, Jones, \& Riley, 2013). The list of negative social, emotional, and biological outcomes associated with PTE is long and includes delinquency, emotional duress, suicidal ideation, substance abuse, aggre sive behavior, limited educational attainment, memory and learning impairment, alexithymia, serious physical diseases, and fractious social relationships (Adams et al., 2013; Betancourt et al., 2012; Carrion \& Wong, 2012; De Bellis \& Zisk, 2014; Felitti et al., 1998; Leenarts et al., 2013; Suzuki et al., 2014). Additionally, biological studies of stress impact have demonstrated that serial exposure to traumatic events may increase the negative ramifications of subsequent exposure to PTE (De Bellis \& Zisk, 2014).

Given the extremely common occurrence and vast possibility for negative impact, it is clear that the role of PTE in mental health deserves significant attention. This is especially true in instances in which negative reactions to PTE precipitate symptoms sufficiently severe to yield a diagnosis of PTSD. Research indicates that this may occur from approximately 5\% (Merikangas et al., 2010) to up to 30\% of the time (Runyon, Deblinger, Behl, \& Cooper, 2006). Careful attention to accurately identifying these cases will enable appropriate evidence-based treatments to be selected and integrated into other service delivery as appropriate.

Thus, this study focuses on the rate of exposure to PTE in youth presenting to a statewide, comprehensive provider of children's behavioral health services in 
the Southeastern United States and the need to integrate a trauma-informed care approach across the system of care. A secondary purpose of the study was to determine the rate of endorsement of symptoms of PTSD in youth who endorsed exposure to one or more PTE.

\section{Methods}

Under agency policy, all new clients receive a trauma screen and, where applicable, trauma assessment (Ebesutani, Ale, Luebbe, Viana, \& Young, 2011). Data for the current effort were gathered via chart review of trauma screens and assessments as typically administered in the course of clinical care. Charts were produced by 35 licensed, Masters-level mental health providers from across the system of care. These clinicians provided services to 175 youth across a diversity of clinical foci, including services provided through a family preservation and reunification program $(49.7 \%$ of the sample), intensive in-home services $(25.1 \%)$, emergency shelters $(24.0 \%)$, and therapeutic foster care $(1.1 \%)$. Providers were asked to submit all trauma screens and assessments that were administered over a period of several months during routine clinical practice. The youth treated in this sample of charts ranged in age from 2 to 18 (mean=11) and were $50.3 \%$ male, 61.8\% Caucasian, 36.4\% African American, and 1.8\% other minority race or ethnicity.

Trauma screening was accomplished with the Trauma History Questionnaire (THQ), a 15-item self-report measure developed by the Yale Child Study Center Childhood Violent Trauma Clinic. The THQ systematically assesses for exposure to a number of possible PTE. If the child has been exposed to an event, the child is asked to rate how much the event affected him or her on a 5-point scale (not at all to extremely) at the time it occurred as well as at the time of the questionnaire. If a client endorsed exposure to one or more PTE, the clinician would administer the UCLA PTSD Reaction Index (PTSD-RI; Pynoos, Rodriguez, Steinberg, Stuber, \& Frederick, 1998; Steinberg et al., 2013). The PTSD-RI is a self-report questionnaire assessing frequency of occurrence of symptoms of PTSD in the past month. Although both instruments were originally designed as self-report tools, they were administered as face-to-face interviews in this study. This was due to the low cognitive functioning and delays in educational achievement seen in many clients served by this agency, which may have impaired the successful completion of penand-paper versions of the measures.

\section{Results}

Ninety-five percent of the sample $(n=167)$ reported exposure to at least one PTE (mean $=5$, standard deviation $[S D]=3.2$, range $=0-15$ ). The most common number of traumas reported (mode) was 3 . No differences in the prevalence of exposure to PTE were found comparing individuals across age, gender, race, ethnicity, or program of service. Becoming unexpectedly separated from a caregiver was the most common event $(67.4 \%)$, followed by witnessing interpersonal violence 
(60.0\%), and being close to someone dying (60.0\%; see Table 1 for full results). Interestingly, abuse and neglect were not the most common PTE. Physical abuse was the 5th most common event (41.1\%), sexual abuse was 10th (21.1\%), and neglect was 11th (20.0\%) out of 15 possible events. Given the salience of these events, and their particular resonance in professions focused on promoting adjustment and health in children and adolescents, it is possible that biased estimation may have led one to believe that these events were more common than was observed in this sample.

Thus, in 167 cases the PTSD-RI was administered to determine the severity of impact of PTE on youths' emotional states. Eleven symptoms were assessed with this instrument in terms of acute reactions (i.e., at the time of the event). One hundred eight clients (64.7\% of those reporting PTE) reported at least 1 acute reaction. Among those, the average number of symptoms reported was $5(S D=2.6$; range $=$ $0-11$ ), while the most common number was 6 . A total of 22 possible longer-term symptoms were also assessed in terms of their frequency in the past month. A total of 111 clients (66.5\% of those reporting PTE) reported at least one symptom that continued to bother them at least "a little" in the past month. Among clients reporting past-month symptoms, 100 (or 90.0\%) reported at least one symptom that bothered them "much" or "most" ( 3 or 4 on a scale of 0 to 4). The average number of past-month symptoms causing significant disturbance was $6(S D=4.9$; range $=0-22)$, whereas the median was 5 .

A final analysis involved the frequency of individuals reporting significant long-term impairment due to their previous PTE. This entailed endorsement of 5 or more symptoms on the PTSD-RI at a 3 or 4 , which was determined to be a significant burden based on 5 as the mean number of PTSD symptoms endorsed by the sample as a whole and "much" or "most" representing a significant degree of symptomatology. Results indicated that approximately $35 \%$ of clients reporting exposure to PTE met these criteria, which represents fully $33 \%$ of the overall sample. Put another way, a third of children admitted to this system of care reported experiencing a significant, potentially impairing burden related to symptoms of PTSD. Although not diagnostic, the high frequency and severity of symptoms is telling, and underscores the need for attention to PTE in treatment of youth. 
Table 1: Rate of Potentially Traumatic Events (PTE) in Children Receiving Mental and Behavioral Health Services

\begin{tabular}{lcc}
\hline PTE in Order of Prevalence & $\mathrm{n}$ & $\%$ \\
\hline $\begin{array}{l}\text { Unexpectedly separated from someone you depend on for love } \\
\text { or security for more than a few days }\end{array}$ & 118 & 67.4 \\
Seen or heard people physically fighting or threatening to hurt each other & 105 & 60.0 \\
Someone close to you died & 105 & 60.0 \\
Witnessed a family member who was arrested or in jail & 89 & 50.9 \\
Someone ever physically hurt you or threatened to hurt you & 72 & 41.1 \\
Someone close to you ever been so badly injured or sick that & 71 & 40.6 \\
$\quad$ s/he almost died & 59 & 33.7 \\
Attacked by a dog or other animal & 58 & 33.1 \\
Seen or been in a really bad accident & 55 & 31.4 \\
Watched people use drugs & 37 & 21.1 \\
Someone made you see or do something sexual, or seen/heard & & \\
$\quad$ someone else being forced to do sex acts & 35 & 20.0 \\
Had a time in your life when you did not have a place to live & 27 & 15.4 \\
$\quad$ or enough food & 21 & 12.0 \\
Someone close to you ever tried to hurt/kill self & 20 & 11.4 \\
So sick that you or the doctor thought you might die & 9 & 5.1 \\
Been mugged or seen someone you care about mugged & & \\
Been kidnapped & & \\
\hline
\end{tabular}

Note. PTE $=$ Potentially Traumatic Event

\section{Discussion}

Exposure to PTE was common in this community-based sample and was consistent with previously published examinations of youth in restrictive environments (e.g., residential treatment and juvenile detention). It was notable that the average exposure to PTE (5) suggested repeated intersection with these difficult events. Consistent with previously reviewed studies and models for symptom development, the serial, diverse nature of exposure has contributed to the complex psychopathology notable in this relatively severe sample (Ehlers \& Clark, 2000; Hodges et al., 2013). Viewed from another perspective, it is possible the severity of the sample is the reason that substantial previous exposure to PTE was found. Although neither statement is causal, that the experience of PTE was common across almost the entire sample speaks to the importance of integrating appropriate strategies for treatment into the system of care.

Specifically, these findings underscore the need to conduct a thorough assessment for PTE and PTSD symptoms at the beginning of any type of mental health intervention in youth (Kisiel, Conradi, Fehrenbach, Torgersen, \& Briggs, 2014), consistent with guidelines from the American Academy of Child and Adolescent Psychiatry (2010). To the degree that interfering symptoms are found, there are several evidence-based treatments available, the most well-researched of which is Trauma-Focused Cognitive Behavior Therapy (TF-CBT; Cohen, Mannarino, \& Deblinger, 2012). Enhancing treatment environments to emphasize trauma-informed 
approaches may also aid in attending to PTE in the course of service delivery. Such a universal precautions approach, particularly when applied to extremely severe clinical populations or intensive service settings (such as residential treatment), is designed for clients who have experienced trauma.

This method of adapting service delivery of trauma-informed care across an entire agency is feasible for implementation in large, often chaotic service systems (Conners-Burrow et al., 2013). Additionally, this approach may reduce the likelihood that clients experience treatment-related traumas, a phenomenon that has been well-documented in the literature on inpatient hospitalization and use of seclusion and restraint (Bonner, Lowe, Rawcliffe, \& Wellman, 2002; Mohr, Mahon, \& Noone, 1998).

Information on trauma-informed care is available from large mental health research organizations (e.g., the National Center for Trauma-Informed Care \& Alternatives to Seclusion and Restraint [beta.samhsa.gov/nctic]), and formal models exist to guide organizations wishing to incorporate these ideas. These include Sanctuary (Bloom, 2005), the Restorative Approach (Wilcox, 2012), and Risking Connection (Brown, Baker, \& Wilcox, 2012), although there are varying degrees of research evidence to support their usage. The Sanctuary model currently has the most support, while the Risking Connection team is currently gathering data to establish it as an evidence-based practice.

Other notable findings in the current study dovetail with the discussion above, particularly in terms of emphasizing the importance of collecting accurate data and dispelling myths about trauma. For example, abuse and neglect were not the most common traumatic stressors experienced by youth in this sample and were not consistently cited as the most distressing experiences. This was the case despite a large percentage of cases being referred from contexts where these experiences were likely quite common (i.e., family preservation programs). Childcare workers and clinicians working with youth should be aware that many types of experiences may be traumatic to youth beyond the usual suspects, which is an overt component of trauma-informed care models. Additionally, individuals working with youth should be sensitive and wide-ranging when questioning youth about past experiences that may still affect them. Although separation from a caregiver is not a Criterion A event according to the DSM (involving actual or threatened death or serious harm to self or other), it is nevertheless an event that causes great disruption in the lives and relationships of children, and may be experienced as traumatic.

Furthermore, it is important for childcare workers and mental health professionals to understand that trauma may impact a youth on a daily basis. In a cognitive model of emotion, for example, a youth may be suddenly overcome by a distressing memory or flashback, which could lead to physical symptoms of a racing heart, upset stomach, and tense muscles, which in turn could provide the impetus for behavior that appears to be disobedient or oppositional in the course of experiencing the memory. Also, when viewed through a functional framework, a youth 
may be unaware of his or her surroundings due to logical, predictable, discernible symptoms of PTSD. Reactions to these behaviors by treatment staff or parents may be softened significantly when they understand what is occurring, which is a component of formal evidence-based interventions (e.g., Cohen et al., 2012) and trauma-informed care more generally.

\section{Case Example Using Trauma-Informed Care}

Anthony is an 8-year-old boy who recently came to live with his foster parents, Mr. and Mrs. Smith, with the eventual goal of adoption into the Smith family. Anthony was in a serious motor vehicle accident several months prior to joining the Smith household. He sustained serious injuries and also witnessed adults being critically injured. After a few weeks of Anthony's living with them, Mr. and Mrs. Smith report to Anthony's social worker that they are having trouble with Anthony refusing to travel in the car when it is time to go somewhere. He often refuses and yells "No!" He makes up excuses to avoid being in a car. When Mrs. Smith tries to make Anthony get in the car, he starts to "act funny," like he doesn't know she is there, and if she touches his arm to "get him out of the trance," he angrily runs away from her. Anthony's social worker explains to the Smiths that Anthony may be dissociating, or becoming so involved in a prior memory of his traumatic experience that he no longer fully realizes where he is or what he is doing. She explains that his "disobedient" behavior during these times is best thought of as a result of posttraumatic stress, and not because Anthony wants to misbehave or be noncompliant. She offers the Smiths a referral to a therapist who can provide Trauma-Focused Cognitive Behavioral Therapy (TF-CBT) at a community mental health center that is committed to providing a trauma-informed care environment. The Smiths and Anthony agree to treatment and attend 12 sessions of TF-CBT. After learning about trauma, processing his experience of the car accident, and working through the skills entailed in treatment within the supportive environment provided by the Smiths, Anthony is able to ride in an automobile again without becoming overwhelmed by his memories or fears.

\section{Limitations}

The current study does have several limitations. The chart review methodology could have led to biased results in that clinicians may have selectively submitted positive trauma screens and assessments, or may have administered questionnaires only to youth they believed had been exposed to trauma. However, due to agency protocol and study design, we believe this risk to be minimal. An additional limitation of this study is due to the demographics of youth attending the programs where these data were collected. The agency serves a primarily rural, low-income population; therefore, these results may not be applicable to other groups. Furthermore, how these results may apply to traditional outpatient populations is unknown. 


\section{Conclusion}

The vast majority of youth in this sample had been exposed to multiple PTE, and PTSD symptoms were found to be common. A significant proportion of the sample experienced current distressing and impairing symptoms. It is vital that childcare workers and mental health clinicians be prepared to work with children and adolescents with trauma histories, and trauma-informed care models are recommended for providing a universal and structured approach. Trauma pervasively affects the thoughts, feelings, behaviors, and relationships of youth receiving mental health services, and childcare workers and mental health clinicians must be prepared with sensitive and comprehensive approaches to service delivery.

Table 1: Rate of PTE in Children Receiving Mental and Behavioral Health Services

\begin{tabular}{lcc}
\hline PTE in Order of Prevalence & $\mathrm{n}$ & $\%$ \\
\hline Unexpectedly separated from someone you depend on for love & & \\
$\quad$ or security for more than a few days & 118 & 67.4 \\
Seen or heard people physically fighting or threatening to hurt each other & 105 & 60.0 \\
Someone close to you died & 105 & 60.0 \\
Witnessed a family member who was arrested or in jail & 89 & 50.9 \\
Someone ever physically hurt you or threatened to hurt you & 72 & 41.1 \\
Someone close to you ever been so badly injured or sick that & 71 & 40.6 \\
$\quad$ s/he almost died & 59 & 33.7 \\
Attacked by a dog or other animal & 58 & 33.1 \\
Seen or been in a really bad accident & 55 & 31.4 \\
Watched people use drugs & 37 & 21.1 \\
Someone made you see or do something sexual, or seen/heard & & \\
$\quad$ someone else being forced to do sex acts & 35 & 20.0 \\
Had a time in your life when you did not have a place to live & 27 & 15.4 \\
$\quad$ or enough food & 21 & 12.0 \\
Someone close to you ever tried to hurt/kill self & 20 & 11.4 \\
So sick that you or the doctor thought you might die & 9 & 5.1 \\
Been mugged or seen someone you care about mugged & & \\
Been kidnapped & & \\
\hline
\end{tabular}

Note. PTE $=$ Potentially Traumatic Event 


\section{References}

Abram, K. M., Teplin, L. A., Charles, D. R., Longworth, S. L., McClelland, G. M., \& Dulcan, M. K. (2004). Posttraumatic stress disorder and trauma in youth in juvenile detention. Archives of General Psychiatry, 61(4), 403-410. doi: 10.1001/archpsyc.61.4.403

Adams, Z. W., McCart, M. R., Zajac, K., Danielson, C. K., Sawyer, G. K., Saunders, B. E., \& Kilpatrick, D. G. (2013). Psychiatric problems and trauma exposure in nondetained delinquent and nondelinquent adolescents. Journal of Clinical Child and Adolescent Psychology, 42(3), 323-331. doi: http://dx.doi. org/10.1080/15374416.2012.749786

American Psychiatric Association. (2000). Diagnostic and statistical manual of mental disorders (4th ed., Text Revision). Washington, DC: American Psychiatric Association.

American Psychiatric Association. (2013). Diagnostic and statistical manual of mental disorders (5th ed.). Arlington, VA: American Psychiatric Publishing.

Beck, J. S. (2011). Cognitive behavior therapy: Basics and beyond (2nd ed.). New York, NY: Guilford Press.

Betancourt, T. S., Newnham, E. A., Layne, C. M., Kim, S., Steinberg, A. M., Ellis, H., \& Birman, D. (2012). Trauma history and psychopathology in war affected refugee children referred for trauma related mental health services in the United States. Journal of Traumatic Stress, 25(6), 682-690. doi: http:// dx.doi.org/10.1002/jts. 21749

Bloom, S. L. (2005). The Sanctuary Model of organizational change for children's residential treatment. Therapeutic Communities, 26(1), 61-78.

Bonner, G., Lowe, T., Rawcliffe, D., \& Wellman, N. (2002). Trauma for all: A pilot study of the subjective experience of physical restraint for mental health inpatients and staff in the UK. J Psychiatr Ment Health Nurs, 9(4), 465-473. doi: http://dx.doi.org/10.1046/j.1365-2850.2002.00504.x

Brown, S. M., Baker, C. N., \& Wilcox, P. (2012). Risking Connection trauma training: A pathway toward trauma-informed care in child congregate care settings. Psychological Trauma: Theory, Research, Practice, and Policy, 4(5), 507-515. doi: http://dx.doi.org/10.1037/a0025269 
Carrion, V. G., \& Wong, S. S. (2012). Can traumatic stress alter the brain? Understanding the implications of early trauma on brain development and learning. Journal of Adolescent Health, 51(2, Suppl), S23-S28. doi: http://dx.doi. org/10.1016/j.jadohealth.2012.04.010

Cohen, J. A., Bukstein, O., Walter, H., Benson, R. S., Chrisman, A., Farchione, T. R., \& Stock, S. (2010). Practice parameter for the assessment and treatment of children and adolescent with posttraumatic stress disorder. Journal of the American Academy of Child \& Adolescent Psychiatry, 49(4), 414-430. doi: http://dx.doi.org/10.1097/00004583-201004000-00021

Cohen, J. A., Mannarino, A. P., \& Deblinger, E. (2012). Trauma-focused CBT for children and adolescents: Treatment applications. New York, NY: Guilford Press.

Conners-Burrow, N. A., Kramer, T. L., Sigel, B. A., Helpenstill, K., Sievers, C., \& McKelvey, L. (2013). Trauma-informed care training in a child welfare system: Moving it to the front line. Children and Youth Services Review, 35(11), 1830-1835. doi: http://dx.doi.org/10.1016/j.childyouth.2013.08.013

De Bellis, M. D., \& Zisk, A. (2014). The biological effects of childhood trauma. Child and Adolescent Psychiatric Clinics of North America, 23(2), 185-222. doi: http://dx.doi.org/10.1016/j.chc.2014.01.002

Ebesutani, C., Ale, C., Luebbe, A., Viana, A., \& Young, J. (2011). A practical guide for implementing evidence-based assessment in a psychiatric residential treatment facility: Translating theory into practice. Residential Treatment for Children \& Youth, 28(3), 211-231. doi: http://dx.doi.org/10.1080/088657 1x.2011.596737

Ehlers, A., \& Clark, D. M. (2000). A cognitive model of posttraumatic stress disorder. Behaviour Research and Therapy, 38(4), 319-345. doi: http://dx.doi. org/10.1016/s0005-7967(99)00123-0

Felitti, V. J., Anda, R. F., Nordenberg, D., Williamson, D. F., Spitz, A. M., Edwards, V., \& Marks, J. S. (1998). Relationship of childhood abuse and household dysfunction to many of the leading causes of death in adults: The Adverse Childhood Experiences (ACE) Study. American Journal of Preventive Medicine, 14(4), 245-258. doi: http://dx.doi.org/10.1016/s0749-3797(98)00017-8 
Finkelhor, D., Turner, H., Ormrod, R., \& Hamby, S. L. (2009). Violence, abuse, and crime exposure in a national sample of children and youth. Pediatrics, 124(5), 1411-1423. doi: http://dx.doi.org/10.1542/peds.2009-0467

Gonzalez-Prendes, A. A., \& Resko, S. M. (2012). Cognitive-behavioral theory. In S. R. J. Brandell (Ed.), Trauma: Contemporary directions in theory, practice, and research. SAGE Publications. doi: http://dx.doi. org/10.4135/9781452230597

Harr, C. R., Horn-Johnson, T. C., Williams, N. J., Jones, M., \& Riley, K. (2013). Personal trauma and risk behaviors among youth entering residential treatment. Child \& Adolescent Social Work Journal, 30(5), 383-398. doi: http:// dx.doi.org/10.1007/s10560-013-0297-1

Hodges, M., Godbout, N., Briere, J., Lanktree, C., Gilbert, A., \& Kletzka, N. T. (2013). Cumulative trauma and symptom complexity in children: A path analysis. Child Abuse \& Neglect, 37(11), 891-898. doi: http://dx.doi. org/10.1016/j.chiabu.2013.04.001

Kisiel, C., Conradi, L., Fehrenbach, T., Torgersen, E., \& Briggs, E. C. (2014). Assessing the effects of trauma in children and adolescents in practice settings. Child and Adolescent Psychiatric Clinics of North America, 23(2), 223242. doi: http://dx.doi.org/10.1016/j.chc.2013.12.007

Leenarts, L. E. W., Vermeiren, R. R. J. M., van de Ven, P. M., Lodewijks, H. P. B., Doreleijers, T. A. H., \& Lindauer, R. J. L. (2013). Relationships between interpersonal trauma, symptoms of posttraumatic stress disorder, and other mental health problems in girls in compulsory residential care. Journal of Traumatic Stress, 26(4), 526-529. doi: http://dx.doi.org/10.1002/jts.21831

Merikangas, K. R., He, J. P., Burstein, M., Swanson, S. A., Avenevoli, S., Cui, L., \& Swendsen, J. (2010). Lifetime prevalence of mental disorders in U.S. adolescents: Results from the National Comorbidity Survey ReplicationAdolescent Supplement (NCS-A). Journal of the American Academy of Child \& Adolescent Psychiatry, 49(10), 980-989. doi: S0890-8567(10)00476-4 [pii] 10.1016/j.jaac.2010.05.017

Mohr, W. K., Mahon, M. M., \& Noone, M. J. (1998). A restraint on restraints: The need to reconsider the use of restrictive interventions. Archives of Psychiatric Nursing, 12(2), 95-106. doi: S0883-9417(98)80059-9 [pii] 
Monson, C. M., \& Friedman, M. J. (2006). Back to the future of understanding trauma: Implications for cognitive-behavioral therapies for trauma. In V. C. F. J. I. Ruzek (Ed.), Cognitive-behavioral therapies for trauma, (2nd Ed.) (pp. 1_16). New York, NY: Guilford Press.

Pynoos, R., Rodriguez, N., Steinberg, A., Stuber, M., \& Frederick, C. (1998). UCLA PTSD Index for DSM IV. Los Angeles, CA: UCLA Trauma Psychiatry Service.

Riggs, D. S., Cahill, S. P., \& Foa, E. B. (2006). Prolonged exposure treatment of posttraumatic stress disorder. In V. M. Follette \& J. I. Ruzek (Eds.), Cognitive-behavioral therapies for trauma, (2nd ed.). (pp. 65-95). New York, NY: Guilford Press.

Runyon, M. K., Deblinger, E., Behl, L., \& Cooper, B. (2006). Post-traumatic stress disorder. In R. T. Ammerman (Ed.), Comprehensive handbook of personality and psychopathology, Vol. 3. (pp. 148-164). Hoboken, NJ: John Wiley \& Sons, Inc.

Steinberg, A. M., Brymer, M. J., Kim, S., Briggs, E. C., Ippen, C. G., Ostrowski, S. A., ... Pynoos, R. S. (2013). Psychometric properties of the UCLA PTSD Reaction Index: Part I. Journal of Traumatic Stress, 26(1), 1-9. doi: http:// dx.doi.org/10.1002/jts. 21780

Suzuki, H., Luby, J. L., Botteron, K. N., Dietrich, R., McAvoy, M. P., \& Barch, D. M. (2014). Early life stress and trauma and enhanced limbic activation to emotionally valenced faces in depressed and healthy children. Journal of the American Academy of Child \& Adolescent Psychiatry, 53(7), 800-813. doi: http://dx.doi.org/10.1016/j.jaac.2014.04.013

Wilcox, P. D. (2012). Trauma-informed treatment: The restorative approach. Holyoke, MA: NEARI Press. 